\title{
Spiritual Well-Being among College Students: Study in Java Province-Indonesia and Hangzhou Province-China
}

\author{
Achmad Sholeh ${ }^{1}$, Hazhira Qudsyi ${ }^{2}$, Fani Eka Nurtjahjo ${ }^{3}$, Nyda Afsari ${ }^{4}$, Hanifah Nur Fitriani ${ }^{5}$, \\ Shuang Geng ${ }^{6}$, Jiayao $\mathrm{Liu}^{7}, \mathrm{Xin} \mathrm{Wen}^{8}$, Mengyan $\mathrm{Xu}^{9}$
}

Department of Psychology, Universitas Islam Indonesia ${ }^{1,2,3,4,5}$

Zhejiang University, China ${ }^{6,7,8,9}$

\begin{abstract}
ARTICLE INFO
Keywords:

Spiritual Well-Being,

Indonesia, China,

Diversity, Cross-

Cultural, Religion

ABSTRACT

This study aims to determine to compare spiritual well-being among college students in Indonesia and China. This Study conducts a quantitative approach and performed in Java Province (Yogyakarta City and Surabaya City), Indonesia and Hangzhou Province, China. The subjects in this study are 50 Indonesia students and 50 China students. Measurement of spiritual well-being used The Spiritual Well-being Scale (SWBS) by Darvyri et al. (2014)This study used independent sample test to compare spiritual well-being among college students in both countries Indonesia and China. The results were consistent with the study hypotheses, indicate that there is different spiritual well-being among college students in Indonesia and China. It is shown from the value of $t=13.52$ with the significance of $p=0.00$. Spiritual well-being of Indonesia students is higher than China students. From the results, it can be concluded that there is a different level of spiritual well-being among Indonesia students and China students, this study identified both countries have a big difference related belief in life.
\end{abstract}

\section{Introduction}

The discussion of spirituality surely cannot be separated from the discussion about religion. However, connection between spirituality and religion is still causing a debate (Fernando \& Chowdhury, 2010). Spirituality and religion are a very complex phenomenon, multidimensional and difficult to define, so it triggers various perspectives and limitations (Hill et al., 2003). On the other hand, some studies stated that spirituality and religion are positively correlated with each other significantly (Haghighi, Najarkolaei, Ansarian, \& Mesri, 2015; Lun \& Bond, 2013; Unterrainer, Lewis, \& Fink, 2014). Spirituality can be seen as a life which is more immaterial (spiritual) or subjective, related to personal experiences that is related with God or higher beings (Thoresen \& Harris, 2002), yet religion is regarded as a more inclusive concept which is the search for meaning with certain rules or rituals; thus, religion is often identified with the religious institutions which is formal, rigid, and structured (Hill et al., 2003; Pargament, 1999; Thoresen \& 
Harris, 2002). These two areas have their respective areas and do not overlap each other (Thoresen, 1999), they are supporting each other and inseparable.

The closest construct to explain spirituality is the concept of spiritual well-being. Darvyri et al., (2014) suggested that spiritual well-being is explained in two ways, namely 1) vertical, which refers to the welfare of God or a higher power, referring to religious elements, and 2) horizontally, which refers to the purpose and satisfaction of life, referring to the spiritual component or existence. In line with that, Hawks explained that spiritual well-being has been applied as a feeling of interrelation or connection to one another, determination of the meaning and purpose of life, and having trust and relationships with a higher power than oneself (Imam, Karim, Jusoh, \& Mamad, 2009).

According to Paloutzian, Emmons, and Keortge, spiritual well-being is seen as an effort to achieve goals which are consistent with someone's spiritual values and its function in their social environment as a whole (Fry, 2005). The main element of spiritual well-being is the ability to be attached in a meaningful and valuable behavior as someone's life call or life purpose (Fry, 2005). Moberg also explained that spiritual well-being is an outcome of someone's spiritual experience which refers to prosperity or health from a person's totality resources, the attention which is focused on the whole value, the main life philosophy which guides regulation, and the giving of meaning in human life which affect all individual behavior and social environment (Fernando \& Chowdhury, 2010).

Spiritual well-being is closely related to positive psychology and can influence a person's mental health, such as psychological adjustment, marriage satisfaction, physical health, social adjustment, coping skills, resilience in facing stress, and to face personal crises (Beery, Baas, Fowler, \& Allen, 2002; Fernando \& Chowdhury, 2010; Fernsler, Klemm, \& Miller, 1999; Robert, Young, \& Kelly, 2006), sleep quality (Eslami, Rabiei, Khayri, Rashidi Nooshabadi, \& Masoudi, 2014; Khoramirad, Mousavi, Dadkhahtehrani, \& Pourmarzi, 2015), happiness and emotional intelligence (Sajjadian et al., 2016), life satisfaction and quality of life (Alorani \& Alradaydeh, 2017; Sharajabad, Mohammad-Alizadeh Charandabi, \& Mirghafourvand, 2017; Vahedi \& Nazari, 2011), even it is able to predict one's moral behavior (Qudsyi, Nurjtahjo, Afsari, Fitriani, \& Sholeh, 2018). Thus, it can be interpreted that spiritual well-being has a very important role for individual's life and health.

Every individual has a different spirituality, as well as different countries and cultures (Lun \& Bond, 2013). Therefore, the problem of spiritual well-being needs to be explored further in crosscultural contexts. This study aimed to understand the spiritual well-being of Indonesia and China. Both countries have several similarities and differences. Indonesia and China are among the top five countries with the largest population in the world, being part of Asia, these two countries generally have a type of society similar to collectivism, but their values and beliefs are certainly much different

(Hofstede, 2011; Novitasari, Qudsyi, Ambarito, \& Yudhani, 2018). Indonesia is dominated by Islam, which has an important role in the country's cultural development (Sallquist, Eisenberg, French, Purwono, \& Suryanti, 2010), as well as China which is dominated by Taoism and Buddhist religion. So far, cross-cultural research on spiritual well-being between Indonesia and China has not been widely studied.

Several research results on spiritual well-being in each country showed a positive impact on social life and individual health (French, Eisenberg, Vaughan, Purwono, \& Suryanti, 2008; Lou, 2015). However, cultural factors from Indonesia and China cannot be excluded. Culture has a very important role in influencing individual experiences. Culture is conceptualized as an agreed system 
and shared meaning, so that it becomes a distinction between one and another group, because it is considered capable of influencing one's spirituality (Lun \& Bond, 2013). Research conducted by Lun and Bond (2013) showed that every national culture context in each country has a different role for spirituality and religion, including the culture of Indonesia and China (Hong Kong) (Lun \& Bond, 2013).

Based in the discussion above, this research would analyze spiritual well-being of university students in Indonesia and China. Thus, the research question was "are there any differences in spiritual well-being of university students in Indonesia and China?"

\section{Research Method}

A. Participant

The participant in this research was 50 university students from Indonesia, taken specifically from Yogyakarta, and 50 students from Zhejiang University, Hangzhou, China.

\section{B. Data Collection Method}

The research was done quantitatively to test the spiritual well-being differences in university students from Indonesia and China. The data collection method was carried out by scale of selfreport for spiritual well-being adapted from spiritual well-being scale by Darvyri et al., (2014). The reliability coefficient of Cronbach Alpha in the original spiritual well-being scale was 0.882 (affiliation with God), 0.738 (satisfaction with life), and 0.669 (alienation from God-sense of meaningless life).

\section{Data Analysis Method}

This research carried out independent samples test analysis method for testing the difference of spiritual well-being between university students from Indonesia and China.

\section{Research Result}

This research aimed at testing the differences empirically to see if there were differences of spiritual well-being in university students from Indonesia and China. The result of data collection can be seen in Table 1 below.

Table 1. The Result of SWB Difference Test

Variable Country Mean $\mathrm{T} \quad \mathrm{N}$

Spiritual Well-Being Indonesia $101.6 \quad 13.52 * * \quad 50$

China $68.56 \quad 50$

Based on the results of data analysis by using the independent sample test, the results indicated that there was a very significant difference between spiritual well-being between Indonesian and Chinese students. These results were obtained from $t$ value $=13.52$ with significance $p=0.00(p$ $<0.01)$. The results of the descriptive analysis also showed that, Indonesia had a higher spiritual well-being with $\mathrm{M}=101.6$, while China had an average of $\mathrm{M}=68.56$. Thus, it could be stated that spiritual well-being of Indonesia and China have differences. 
Table 2. The Result of Difference Test of SWB Aspects

SWB Aspects Country Mean $\mathrm{T}$ N

Affiliation with God Indonesia

China 58.71

$41.2917 .94 * * \quad 50$

50

Satisfaction with Life Indonesia

China 54.25

$45.754 .67 * 50$

50

Alienation from God-Sense of Meaningless Life (Negative) Indonesia

China - 55.45

$-44.55-6.48 * * \quad 50$

50

Based on additional analysis conducted on every aspect of spiritual well-being, the results obtained showed that there were significant differences in each aspect. These results were obtained from the value of $t=17.92$ with significance $p=0.00(p<0.01)$ on the affiliation with God aspect which had a mean of $M=58.71$ for Indonesian students and Chinese students for $M=41.29$. In the aspect of satisfaction with life, the value of $t=4.62$ was obtained with significance $p=0.00(p<0.01)$ with the average of Indonesian for $M=54.25$, while Chinese got an average of $M=45.75$. The third aspect obtained a value of $t=6.64$ with a significance of $p=0.00(p<0.01)$ and an average of Indonesian was $\mathrm{M}=-55.45$, while China obtained a lower mean $\mathrm{M}=-44.55$. Overall, Indonesian students had a higher level of spiritual well-being than Chinese, which were shown in the average of each aspect.

\section{Discussion}

The discussion in this study considered the influence of religion and culture on the results. Indonesian students had a higher spiritual well-being score, compared to students from China. The differences in values and beliefs of Indonesian and China affected the spiritual well-being. Lippman and Keith explained that spirituality and religion are important aspects of everyday life in Indonesian society. In fact, it has a role in social, socio-emotional and individual development (Sallquist et al., 2010). The concepts of spirituality and religion can be seen in the secular domain, and religious commitments are often displayed publicly (French et al., 2008; Sallquist et al., 2010). This is proved by the existence of the religious status stated in official identification cards and also in each demographic database (Sallquist et al., 2010). In fact, religion is a compulsory subject in schools and lectures, even television programs are paused because of the call to prayer (adzan) (French et al., 2008).

Another way to understand the cultural differences between Indonesia and China is through collectivism. The collectivism tradition is the values related to the integration of society, such as those who are related to family, group, and culture itself (Hofstede, 2011; Novitasari et al., 2018). Indonesia has a majority Muslim population with the largest population in the world. Islam contributes to the development of culture in Indonesia, making it very integrated with Indonesian culture and people's private lives. Cultural assimilation is manifested through daily activities such 
as norms in dressing, daily worship (five times prayer) (Mangunjaya \& Elizabeth, 2012), and daily manners (such as eating and drinking, speaking, how to behave, etc.). Islam has a big impact on the lives of the Indonesian people, even other religions are also affected by Islamic values in society. Smith explained that other religions also tended to be influenced by Islamic values, because there is a connection with cultural norms and values (French et al., 2008). The examples are for non-Muslims in Java, there is a tendency not to serve alcohol at banquets or social activities because of religious restrictions, also mosques and churches maintain tolerance and understand each other. Thus, Indonesian culture tends not to separate spirituality and religiosity, so that the relationship in inseparably complex (French et al., 2008; Sallquist et al., 2010).

Meanwhile, the concept of spirituality in Chinese society can be understood through a socialrelations perspective (Lou, 2015). In Chinese society, the core goal of spirituality is to achieve unity with the universe or heaven through a harmonious or balanced relationship with all beings, to have a good and healthy life for them so that it is important to maintain harmony with all spiritual powers, such as the process of the cosmos, Gods and Goddesses, and ancestors who are considered to influence ongoing life in a family (Lou, 2015).

Chinese society tends to separate religion from daily life. The data obtained from Chinese informants showed that Chinese students in Hangzhou Province are known to understand the concept of religion, but do not apply it to everyday life. Religion only functions as knowledge and philosophy. In line with that, Chinese culture is predominantly influenced by Confucianism, which only emphasizes the process of self-transformation and self-development by focusing on creating harmonious relations in the five cardinals, namely father-son, husband and wife, old-young, emperor-subject, and among friends (Lou, 2015).

Chinese culture, which is dominated by Confucianism, actually underestimates the abstract concept of God, and believes more in the relationship between life and death. The relationship between life and death is like two sides of coin that emphasizes certain goals such as the hope of good way to die, which is fast, peaceful and does not burden their descent. Through the relationship of life and death, it is considered able to build meaning for an important life. Then, it was explained that there was no vertical relationship between humans and God, only the relationship between children and their parents was considered as the highest, because they had taken care of and raised their children.

Thus, the concept of spiritual well-being in Chinese culture is on the non-religious side, which is in contrast to Indonesian culture that emphasizes religious interrelationship in understanding spirituality. Correspondingly, the findings in this study proved that affiliation with God in Indonesian students had a higher score than Chinese students. As explained by Chinese informants, when carrying out the SWBS self-report, students had difficulty with the statements that discussed God-related issues, because the majority of them did not have religion but only understood it only as philosophy of life.

These findings are also consistent with previous research by Darvyri et al. (2014), which showed that individuals who have affiliation with God and high satisfaction with life will be inferior to alienation from God-sense of meaningless life, where the concept of spiritual well-being has two cores which are God and satisfaction from life which refers to the spiritual component or existence. Therefore, Indonesia had a higher spiritual well-being score because the religious aspects of religion are inseparable from divine values. Meanwhile, Chinese students actually tended not to care about the concept of God. These results are also supported by several studies, which showed that spirituality and religion are correlated with satisfaction with life, and spiritual beliefs in 
religious contexts help to increase one's life satisfaction (Khan, Shirazi, \& Ahmed, 2011; Sharajabad et al., 2017; Zullig, Ward, \& Horn, 2006).

This study still had several delimitations, which were involving limited subjects so it was difficult to be generalized to the existing populations, and the lack of social-demographic data so that it only prioritized cultural factors without considering demographic data such as gender, age, ethnicity, and religion.

\section{Conclusion}

Based on the analysis and results abovementioned, this study identified differences in spiritual well-being between Indonesian students and Chinese students. It can be concluded that there was a very significant difference in spiritual well-being between Indonesian students and Chinese students. The existence of cultural factors which were influenced by religion and belief toward the different values of life became the cause of the differences in spiritual well-being.

\section{References}

Alorani, O. I., \& Alradaydeh, M. F. (2017). Spiritual well-being, perceived social support, and life satisfaction among university students. International Journal of Adolescence and Youth, 11(4), 330-338. https://doi.org/10.1080/02673843.2017.1352522

Beery, T. A., Baas, L. S., Fowler, C., \& Allen, G. (2002). Spirituality in Persons with Heart Failure. Journal of Holistic Nursing, 20(1), 5-25. https://doi.org/10.1177/089801010202000102

Darvyri, P., Galanakis, M., Avgoustidis, A. G., Vasdekis, S., Artemiadis, A., Tigani, X., Darviri, C. (2014). The Spiritual Well-Being Scale (SWBS) in Greek Population of Attica. Psychology, 05(13), 1575-1582. https://doi.org/10.4236/psych.2014.513168

Eslami, A. A., Rabiei, L., Khayri, F., Rashidi Nooshabadi, M. R., \& Masoudi, R. (2014). Sleep Quality and Spiritual Well-Being in Hemodialysis Patients. Iranian Red Crescent Medical Journal, 16(7). https://doi.org/10.5812/ircmj.17155

Fernando, M., \& Chowdhury, R. M. M. I. (2010). The relationship between spiritual well-being and ethical orientations in decision making: An empirical study with business executives in Australia. Journal of Business Ethics, 95(2), 211-225. https://doi.org/10.1007/s10551-009-0355y

Fernsler, J. I., Klemm, P., \& Miller, M. A. (1999). Spiritual well-being and demands of illness in people with colorectal cancer. Cancer Nursing, 22(2), 134-140. https://doi.org/10.1097/00002820199904000-00005

French, D. C., Eisenberg, N., Vaughan, J., Purwono, U., \& Suryanti, T. A. (2008). Religious Involvement and the Social Competence and Adjustment of Indonesian Muslim Adolescents. Developmental Psychology, 44(2), 597-611. https://doi.org/10.1037/0012-1649.44.2.597

Fry, L. W. (2005). Toward a theory of ethical and spiritual well-being, and corporate social responsibility through spiritual leadership. In Positive psychology in business ethics and corporate responsibility (pp. 47-83). https://doi.org/spi

Haghighi, M., Najarkolaei, F. R., Ansarian, A., \& Mesri, M. (2015). Correlation between Spiritual Wellbeing and Religious Orientation among Staffs of one Military Medical University. Journal of Health, 1(4), 137-140. from http://journals.bmsu.ac.ir/jhpsh/index.php/jhpsh/article/view/20 
Hill, P. C., Pargament, K. I., Hood, R. W., McCullough, M. E., Swyers, J. P., Larson, D. B., \& Zinnbauer, B. J. (2003). Conceptualizing religion and spirituality. Points of Commonality Points of Departure, 2(3), 51-77. Retrieved from http://ovidsp.ovid.com/ovidweb.cgi?T=JS\& $\mathrm{CSC}=\mathrm{Y} \& \mathrm{NEWS}=\mathrm{N} \& \mathrm{PAGE}=$ fulltext $\& \mathrm{D}=$ sopp $\& \mathrm{AN}=43146-031001206$

Hofstede, G. (2011). Dimensionalizing Cultures: The Hofstede Model in Context. Online Readings in Psychology and Culture, 2(1). https://doi.org/10.9707/2307-0919.1014

Imam, S. S. S., Karim, N. H. A. N., Jusoh, N. R., \& Mamad, N. E. (2009). Malay Version of Spiritual Well-being Scale: Is Malay Spiritual Well-Being Scale A Psychometrically Sound Instrument? The Journal of Behavioral Science, 4(1), 72-83. Retrieved from http://ejournals.swu.ac.th/index.php/jbse/article/view/999

Khan, M., Shirazi, M., \& Ahmed, M. (2011). Spirituality and life satisfaction among Adolescents in India. Journal of Subcontinent Researches, 3(7), 71-84. https://doi.org/10.1017 /CBO9781107415324.004

Khoramirad, A., Mousavi, M., Dadkhahtehrani, T., \& Pourmarzi, D. (2015). Relationship Between Sleep Quality and Spiritual Well-Being/Religious Activities in Muslim Women with Breast Cancer. Journal of Religion and Health, 54(6). https://doi.org/10.1007/s10943-014-9978-0

Lou, V. W. Q. (2015). Spiritual Well-Being of Chinese Older Adults. Spinger. Berlin, Heidelberg: Springer Berlin Heidelberg. https://doi.org/10.1007/978-3-662-46303-1

Lun, V. M. C., \& Bond, M. H. (2013). Examining the relation of religion and spirituality to subjective well-being across national cultures. Psychology of Religion and Spirituality, 5(4), 304315. https://doi.org/10.1037/a0033641

Mangunjaya, F. M., \& Elizabeth, J. M. (2012). Reviving an islamic approach for environmental conservation in indonesia. In Worldviews: Environment, Culture, Religion (Vol. 16, pp. 286-305). https://doi.org/10.1163/15685357-01603006

Novitasari, R., Qudsyi, H., Ambarito, T. P., \& Yudhani, E. (2018). A Comparative Study of Subjective Well-Being Among Working Mothers in Indonesia and China. Global Journal of Business and Social Science Review, 6(1), 27-31.

Pargament, K. I. (1999). The Psychology of Religion and Spirituality? Yes and No. The International Journal for the Psychology of Religion, 9(1), 3-16. https://doi.org/10.1207/s15327582ijpr0901_2

Qudsyi, H., Nurjtahjo, F. E., Afsari, N., Fitriani, H. N., \& Sholeh, A. (2018). Spiritual Well-being, Parent Attachment, and Moral Disengagement among College Students. International Journal of Social Science and Humanity, 8(4), 100-104. https://doi.org/10.18178/ijssh.2018.V8.943

Robert, T. E., Young, J. S., \& Kelly, V. A. (2006). Relationships between adult workers' spiritual well-being and job satisfaction: A preliminary study. Counseling and Values, 50(3), 165-175. https://doi.org/10.1002/j.2161-007X.2006.tb00053.x

Sajjadian, P., Kalantari, M., Abedi, M. R., Nilforooshan, P., Abedi, M. R., \& Nilforooshan, P. (2016). Predictive Model of Happiness on the Basis of Positive Psychology Constructs. Review of European Studies, 8(4), 81. https://doi.org/10.5539/res.v8n4p81

Sallquist, J., Eisenberg, N., French, D. C., Purwono, U., \& Suryanti, T. A. (2010). Indonesian adolescents' spiritual and religious experiences and their longitudinal relations with socioemotional functioning. Developmental Psychology, 46(3), 699-716. https://doi.org/10.1037/a0018879

Sharajabad, F. A., Mohammad-Alizadeh Charandabi, S., \& Mirghafourvand, M. (2017). Life satisfaction and its relationship with spiritual well-being and religious practice in Iranian 
adolescent girls. International Journal of Adolescent Medicine and Health. https://doi.org/10.1515/ijamh-2017-0077

Thoresen, C. E. (1999). Spirituality and Health Is There a Relationship? Journal of Health Psychology, 4(3), 291-300. https://doi.org/10.1177/135910539900400314

Thoresen, C. E., \& Harris, A. H. S. (2002). Spirituality and health: What's the evidence and what's needed? Annals of Behavioral Medicine, 24(1), 3-13. https://doi.org/10.1207/S15324796ABM2401_02

Unterrainer, H. F., Lewis, A. J., \& Fink, A. (2014). Religious/Spiritual Well-Being, Personality and Mental Health: A Review of Results and Conceptual Issues. Journal of Religion and Health, 53(2), 382-392. https://doi.org/10.1007/s10943-012-9642-5

Vahedi, S., \& Nazari, M. A. (2011). The Relationship between Self-Alienation, Spiritual WellBeing, Economic Situation and Satisfaction of life: A Structural Equation Modeling Approach. Iranian Journal of Psychiatry and Behavioral Sciences, 5(1), 64-73. Retrieved from https://ijpbs.mazums.ac.ir/article-1-68-en.pdf

Zullig, K. J., Ward, R. M., \& Horn, T. (2006). The association between perceived spirituality, religiosity, and life satisfaction: The mediating role of self-rated health. Social Indicators Research, 79(2), 255-274. https://doi.org/10.1007/s11205-005-4127-5 